\title{
SUSTENTABILIDADE NA INDÚSTRIA DO \\ VESTUÁRIO: ESTUDO DE CASO EM UMA \\ EMPRESA DO SEGMENTO MODA FESTA
}

\section{SUSTAINABILITY IN THE CLOTHING INDUSTRY: CASE STUDY IN A COMPANY IN THE PARTY FASHION SEGMENT}

STELLA TELLES BARROS, M.SC. | UFU

VIVIANE G. A. NUNES, PhD. | UFU

\begin{abstract}
RESUMO
O "progresso" desenfreado especialmente relacionado ao Setor da Moda tem gerado uma série de impactos econômicos, sociais e ambientais, facilmente identificados através de desequilíbrios como a degradação ambiental e a poluição. A partir desse cenário, buscou-se compreender a relação entre a Sustentabilidade e o Sistema Produtivo das Indústrias do Vestuário, com o objetivo de investigar alternativas para sistematizar práticas produtivas voltadas a esse setor estimulando, principalmente, a sustentabilidade ambiental dos processos. Por meio de um estudo de caso em uma indústria do vestuário do segmento de Moda Festa na cidade de Uberlândia/ MG, este trabalho, de natureza qualitativa e caráter exploratório, analisa e discorre sobre o Sistema de Moda e seus elementos, como também, sobre os princípios do Design Sustentável. As reflexões sobre sustentabilidade e moda foram baseadas no referencial teórico mencionado e permitiram identificar o nível de maturidade sustentável da empresa bem como as ações sustentáveis já realizadas. Os resultados gerados contemplam diretrizes gerais para a sistematização gradual de ações voltadas para a sustentabilidade, as quais permitirão orientar as empresas, especialmente do Segmento Moda Festa, a progredir continuamente em direção ao crescimento de seu nível de maturidade sustentável.
\end{abstract}

PALAVRAS-CHAVE: Moda e sustentabilidade; Design e moda; Ciclo produtivo na indústria do vestuário; Segmento moda festa

\begin{abstract}
The unbridled progress, especially that related to the Fashion's Segment, has generated a series of economic, social and environmental impacts easily identified through unbalanced conditions such as environmental degradation and pollution. From this scenario, we sought to understand the relationship between Sustainability and the Apparel Industry Productive System, with the objective of investigating alternatives to systematize productive practices for the apparel industry, mainly stimulating the environmental sustainability of the processes. Through a case study in a clothing industry in the Fashion Party segment in the city of Uberlândia/MG, this work, of a qualitative nature and exploratory character, analyzes and discusses the Fashion System and its elements, as well as the principles of Sustainable Design. The reflections on sustainability and fashion were based on the mentioned theoretical framework and allowed to identify the company's sustainable maturity level and the actions already achieved. The obtained results include general guidelines for the gradual systematization of actions focused on sustainability, which will enable companies especially those from the Fashion Party segment to continuously progress towards the growth of their level of sustainable maturity.
\end{abstract}

KEYWORDS: Fashion and sustainability; Design and fashion; Productive cycle in the clothing industry; Party fashion segment 


\section{INTRODUÇÃO}

Devido ao "progresso" descontrolado, o planeta tem enfrentado, como consequência, uma série de impactos econômicos, sociais e ambientais, os quais são facilmente identificados através de desequilíbrios como a degradação ambiental e a poluição. Diante desse cenário, torna-se cada vez mais necessário, especialmente aos designers e demais profissionais atuantes no Setor Moda, investigar novos caminhos, conhecimentos e formas de pensamento para conciliar o inevitável desenvolvimento econômico com a preservação ambiental (KAZAZIAN, 2005).

$O$ desenvolvimento do presente estudo deve-se ao interesse pelas áreas de Design de Moda, da Sustentabilidade e do Sistema Produtivo das Indústrias da Moda e do Vestuário. De acordo com o Sindicato das Indústrias do Setor do Vestuário de Uberlândia (SINDIVESTU) existem na cidade cerca de 150 micro e pequenas empresas: um quarto delas produz mensalmente a média 5.500 peças e $46 \%$ lançam coleções, com criações próprias, mais de quatro vezes ao ano. As empresas possuem o apoio do sindicato na capacitação para melhoria do desempenho na gestão, produção, uso de tecnologias e ações de mercado, buscando o fortalecimento das indústrias do vestuário de Uberlândia nos negócios globalizados (FIEMG/SINDIVESTU, 2019).

Das 150 micro e pequenas empresas existentes na cidade, 45 delas são do segmento Moda Festa. Tomando como referencial de estudo as Indústrias do Vestuário no segmento Moda Festa da cidade de Uberlândia, percebe-se que durante o processo de desenvolvimento dos produtos são geradas e acumuladas diversas tipologias de resíduos sólidos, tais como retalhos, aviamentos, tubos plásticos e papéis, os quais são descartados sem qualquer real preocupação quanto ao seu destino final. Dos resíduos sólidos produzidos pelas indústrias do vestuário, destaca-se a grande quantidade de resíduos têxteis (retalhos) gerada, devido à dificuldade em descartá-la e pelo fato de estes serem provenientes de uma das matérias-primas mais valiosas das confecções, os tecidos (FIEMG/SINDIVESTU, 2019).

De acordo com Ávila et al. (2018), a cadeia produtiva da moda abrange dois sistemas: o têxtil e o de vestuário. Em ambos os sistemas encontramos práticas que geram resíduos sólidos provenientes da confecção, sendo que grande quantidade das sobras e retalhos é destinada para o descarte inadequado no meio ambiente.

Em Uberlândia, de acordo com o Departamento Municipal de Água e Esgoto (DMAE), a quantidade de resíduos sólidos urbanos produzidos no mês de maio de 2018 foi de 14.802 toneladas, já em maio de 2019 foram produzidas 16.380 toneladas. Ainda segundo o DMAE, em 2019
2,2\% dos resíduos sólidos destinados á coleta pública foram têxteis, ressaltando que esse valor compreende às pequenas confecções, roupas e tecidos descartados pela população na coleta comum e que a cidade não possui um sistema específico para a coleta e a quantificação dos resíduos têxteis industriais.

A partir desse cenário, este trabalho busca compreender a relação entre a Sustentabilidade e o Sistema Produtivo das Indústrias do Vestuário, com o objetivo de investigar alternativas para sistematizar práticas produtivas voltadas a esse setor estimulando, principalmente, a sustentabilidade ambiental dos processos. Por meio de revisão de literatura e estudo de caso em uma indústria do vestuário do segmento de Moda Festa na cidade de Uberlândia/MG, o trabalho, de natureza qualitativa e caráter exploratório, analisa e discorre sobre o Sistema de Moda e seus elementos, sobre os princípios do Design Sustentável e apresenta um grupo de diretrizes.

\section{DESIGN E SUSTENTABILIDADE: ANÁLISE DO CICLO PRODUTIVO DO VESTUÁRIO}

Há algumas décadas uma série de autores tais como Stahel (1982), Papanek (1995), Manzini e Vezzoli (2002) e Kazazian (2005), dentre outros, têm discorrido sobre possíveis caminhos do Design voltado para a Sustentabilidade, sendo algumas destas publicações grandes influenciadoras de ações e pesquisas sobre o tema.

No entanto, O'Brien (2018 apud CESCHIN e GAZIULUSOY, 2020) afirma que, para alcançarmos a sustentabilidade, são necessárias transformações de comportamentos e práticas que formam os sistemas e as estruturas das sociedades, quebrando paradigmas que influenciam na maneira de viver das pessoas. Segundo a Organização das Nações Unidas (ONU, 2016), por exemplo, em 2050 serão necessários três planetas Terra para sustentar o atual estilo de vida da humanidade.

Ainda nos anos 1989/1990, Holanda e Austrália se mobilizaram para desenvolver dois grandes projetos patrocinados pelo governo, o Ecodesign e o EcoReDesign, respectivamente, no sentido de estimular práticas mais sustentáveis de produção a partir de uma visão mais ampliada. Segundo Manzini e Vezzoli, (2002), a preocupação do Ecodesign deve, porém, ocorrer desde o início do ciclo de vida do produto até o seu final, ou seja, abranger desde a extração das matérias-primas, percorrendo o caminho da fabricação, da distribuição, pelo uso e até o descarte final do produto.

Observa-se que os caminhos propostos pelo Ecodesign permitiram identificar e direcionar o perfil dos impactos ambientais causados pelos produtos em todas 
as fases do ciclo de vida, pois, ao avaliar qual a etapa do ciclo de vida do produto gera maiores impactos ambientais negativos, é possível criar orientações estratégicas para essa etapa com intervenções que sejam sustentáveis (MANZINI e VEZZOLI, 2002; SAMPAIO et al, 2018; CESCHIN e GAZIULUSOY, 2020). Assim sendo, as orientações propostas pelo Ecodesign exigem dos designers uma compreensão maior e mais sistêmica sobre os impactos causados em suas decisões dentro das empresas (CESCHIN e GAZIULUSOY, 2020).

O Ecodesign é, portanto, um importante componente das estratégias voltadas para a inovação sistêmica e de longo prazo. Após consolidar seus conceitos e ferramentas, hoje, está direcionadondo às práticas gerenciais e estratégicas. Pigosso, Rozenfeld e McAloone (2013 apud CESCHIN E GAZIULUSOY, 2020), buscam apoiar as práticas de Ecodesign nas empresas, dizendo que é possível diagnosticar seu atual nível sustentável, e permitindo desenvolver roteiros estratégicos para incentivar tais práticas internamente.

Sampaio et al. (2018) também abordam o tema, afirmando que a adoção das estratégias sustentáveis pelas organizações depende do seu estágio de maturidade quanto à sustentabilidade, valendo a ressalva de que esse estágio independe do nível de adoção do design pela organização. Significa que uma empresa pode ter um grau elevado de conhecimentos sobre design e ainda assim não possuir absolutamente nenhum nível de sustentabilidade integrado aos seus critérios para o desenvolvimento de projetos.

Os níveis de maturidade discutidos por Sampaio et al. (2018) são apresentados na Tabela 1.

\begin{tabular}{|l|l|}
\hline \multicolumn{2}{|l|}{ Níveis de Maturidade Sustentável de uma Empresa } \\
\hline $\mathbf{1}^{\circ}$ Inatividade & $\begin{array}{l}\text { Nenhum conhecimento sobre os proble- } \\
\text { mas ambientais ligados aos seus negócios; } \\
\text { nenhuma prática em prol do meio ambiente. }\end{array}$ \\
\hline $\mathbf{2}^{\circ}$ Consciência & $\begin{array}{l}\text { Início do aprendizado sobre os impactos } \\
\text { ambientais gerados pelo negócio; busca por } \\
\text { conhecimentos sobre a sustentabilidade. }\end{array}$ \\
\hline $\begin{array}{l}\mathbf{3}^{\circ} \\
\text { Experimentação }\end{array}$ & $\begin{array}{l}\text { Busca por soluções ambientalmente me- } \\
\text { lhores e/ou práticas consideradas como } \\
\text { disfarce (sem conhecimento da empresa). }\end{array}$ \\
\hline $\begin{array}{l}\mathbf{4}^{\circ} \\
\text { Experimentação } \\
\text { Proativa }\end{array}$ & $\begin{array}{l}\text { Adoção inicial de práticas ambientais } \\
\text { isoladas nos produtos, serviços e pro- } \\
\text { cessos (motivo: aumento da consciência } \\
\text { ambiental ou exigências dos clientes). }\end{array}$ \\
\hline $\mathbf{5}^{\circ}$ Expansão & $\begin{array}{l}\text { Aumento dos projetos com preocupa- } \\
\text { ções ambientais, embora nem todos } \\
\text { coordenados e interligados (motivo: } \\
\text { crença no impacto positivo das ações ou } \\
\text { cobranças de regulamentos e leis). }\end{array}$ \\
\hline $\begin{array}{l}\mathbf{6}^{\circ} \text { Gestão } \\
\text { Integrada }\end{array}$ & $\begin{array}{l}\text { Ações ambientais coordenadas sis- } \\
\text { tematicamente e integradas envol- } \\
\text { vendo todos os seus aspectos. }\end{array}$ \\
\hline
\end{tabular}

\begin{tabular}{|l|l|}
\hline $\begin{array}{l}\mathbf{7}^{\circ} \text { Atuação } \\
\text { Ampliada }\end{array}$ & $\begin{array}{l}\text { Atuação interna e influência externa sobre } \\
\text { padrões de produção e consumo, legislações } \\
\text { e regulamentos ligados ao meio ambiente. }\end{array}$ \\
\hline
\end{tabular}

Tabela 1 - Níveis de Maturidade Sustentável de uma empresa. Fonte: Autores. Baseado em SAMPAI0 et al (2018).

Nesse sentido, entendemos que o Ecodesign representa um grande suporte para que as empresas adotem estratégias sustentáveis; porém, as ações dependem do grau de maturidade que a instituição possui quanto à sustentabilidade e não apenas do seu nível de incorporação do design. Também vale a ressalva de que o Ecodesign baseia-se em todo o ciclo de vida do produto e propõe aos designers orientações que exigem maior compreensão sobre os impactos causados em suas decisões.

\subsection{Ciclo de vida do produto}

É fundamental compreender o ciclo de vida do produto como algo além do tempo de durabilidade, mas como todo o processo de criação, desde o seu nascimento (quando os recursos necessários para a produção dos materiais que o compõe são extraídos) até a sua morte (ultimo tratamento desses materiais após o uso dos produtos, ou seja, um "conjunto de atividades e processos, cada um deles absorvendo certa quantidade de matéria e de energia, operando uma série de transformações e liberando emissões de natureza diversas" (MANZINI e VEZZOLI, 2002, p. 91). O INMETRO (2018, apud SAMPAIO et al, 2018) também conceitua o Ciclo de Vida como a junção, na totalidade, das etapas necessárias para que um produto complete todas as fases fundamentais na cadeia produtiva, desde a extração, passando pelo processamento da matéria prima chegando ao descarte final.

Manzini e Vezzoli (2002) delimitam as fases fundamentais da cadeia produtiva como cinco, sendo elas: 1) PréProdução, 2) Produção, 3) Distribuição, 4) Uso e 5) Descarte.

Ao analisar cada etapa do Ciclo de Vida de um produto, é perceptível que dentro de cada uma delas existem inputs (insumos, energia, água) gastos na produção e descarte, como também outputs (emissões e resíduos) desses processos. $\mathrm{O}$ conceito apresentado pelo Cradle-to-Cradle trabalha os resíduos como nutrientes para novas cadeias ou Ciclos de Vida adicionais, por isso vale a pena destacar que após ou paralelamente à fase de descarte, existem outras etapas que devem ser abordadas. Nesse sentido, o fluxo de materiais pode ser desacelerado e o Ciclo de Vida prolongado adotando-se, também, as etapas de 1) Reutilização, 2) Restauração e 3) Reciclagem (MANZINI e VEZZOLI, 2002; FLETCHER e GROSE, 2011; BRAUNGART e MCDONOUGH, 2013; SAMPAIO et al 2018). 
Realizar a análise do Ciclo de Vida dos produtos como um suporte para o desenvolvimento de projetos permite prever e amenizar os impactos causados ao meio-ambiente e verificar como as mudanças no processo de projetar podem alterar estes impactos. A seguir, tomando como base os estudos realizados pelos autores Manzini e Vezzoli (2002), Fletcher e Grose (2011) e Braungart e McDonough (2013), abordaremos cada uma das etapas propostas para o Ciclo de Vida dos Produtos (Figura 1).

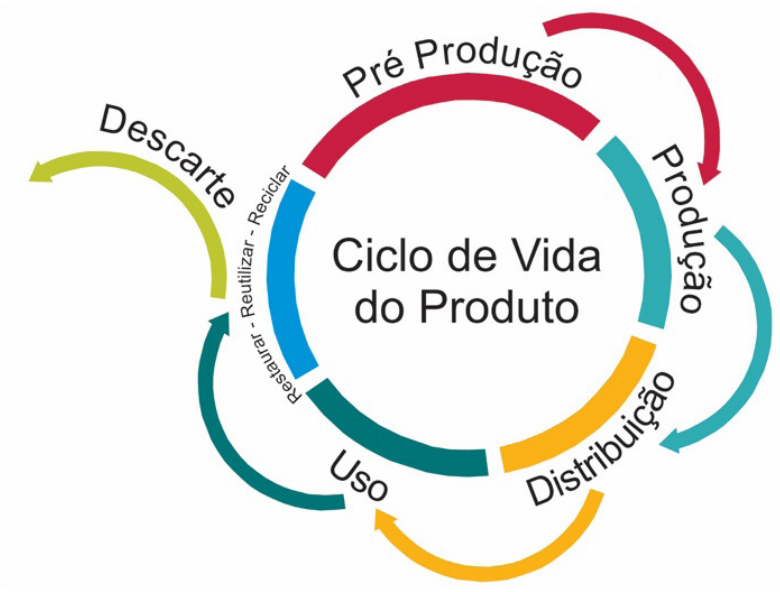

Figura 1 - Ciclo de Vida do Produto.

Fonte: Organizado pelas autoras, baseado em Manzini e Vezzoli (2002), Fletcher e Grose (2011) e Braungart e Mcdonough (2013).

Em todas estas etapas do Ciclo de Vida, sempre haverá interferências na natureza, seja em forma de recursos retirados dela, seja em forma de resíduos do processo lançados no espaço natural. Espera-se, portanto, do designer que ele esteja consciente ao definir as especificações necessárias a cada uma dessas etapas, buscando soluções ecologicamente corretas que sejam viáveis e possam ser adotadas. Mesmo adotando estratégias, procedimentos e materiais corretos, reconhecemos a dificuldade de evitar todas as consequências. Porém, pequenas ações em apenas uma das etapas do projeto, por exemplo, também são consideradas medidas preventivas ou corretivas em relação aos impactos ambientais negativos.

\subsubsection{Ciclo Produtivo da Indústria da Moda}

De acordo Fletcher e Grose (2011), a indústria da moda ainda é muito criticada e tem sido forçada às mudanças pelos processos de sustentabilidade, visando atingir uma postura mais eficiente, respeitosa e menos poluente. Essas mudanças direcionam o setor para o entendimento da interconectividade de suas operações. A visão ampliada do Ciclo de Produção e Consumo do produto de moda pode criar oportunidades de intervir nos impactos sociais e ambientais, buscando alcançar a sustentabilidade continuada.
Fletcher e Grose (2011) discutem o ciclo produtivo da Indústria da Moda, elencando cinco etapas do processo 1) Materiais, 2) Processos, 3) Distribuição, 4) Cuidados do Consumidor e 5) Descarte. As autoras também ressaltam a importância de se pensar de forma sustentável em cada uma das etapas. Cabe destacar que o ciclo produtivo aqui apresentado retrata processos gerais da indústria da moda cujas etapas, dependendo das dimensões da empresa, poderão ser ampliadas e/ou suprimidas (Figura 2).

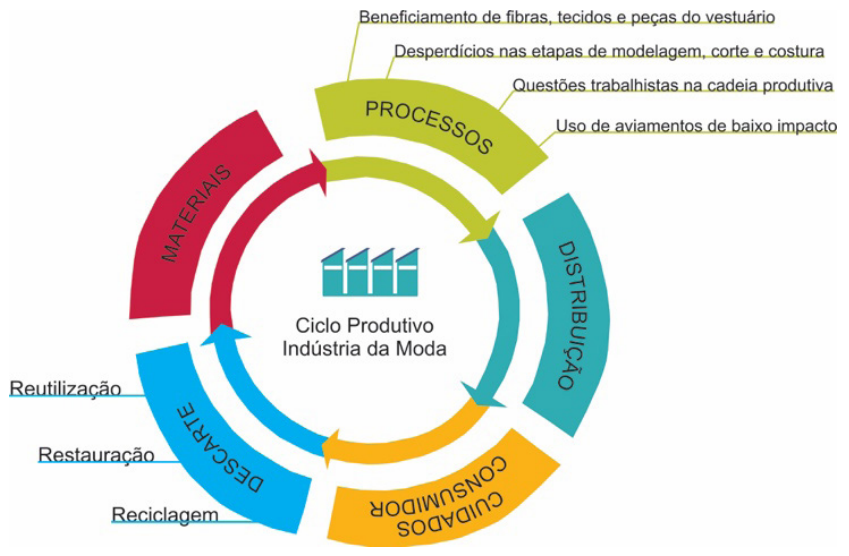

Figura 2 - Ciclo produtivo da Indústria da Moda.

Fonte: Organizado pelas autoras, baseado em Fletcher e Grose (2011).

\subsubsection{Ciclo Produtivo da Indústria do Vestuário}

De forma complementar às autoras Fletcher e Grose (2011), apresentamos outro Ciclo Produtivo, voltado para as Confecções, desenvolvido pela AUDACES. A empresa brasileira fundada em 1992, e situada em Florianópolis/ Santa Catarina, produz tecnologias direcionadas para a indústria do vestuário em mais de 70 países. No e-book "O ciclo de desenvolvimento da peça de vestuário" (AUDACES, 2015), a empresa divide o Ciclo Produtivo das Confecções em três grandes grupos sendo eles: Criação, Desenvolvimento e Produção. Cada um dos grupos é composto por etapas, sendo divididos conforme se segue:

- Criação: composta pelas seguintes etapas: 1) pesquisa de venda; 2) criação de mix de produto; 3) pesquisa e criação, e 4) de engenharia.

- Desenvolvimento: composta pelas seguintes etapas: 1) modelagem; 2) pilotagem; e 3) divulgação para vendas.

- Produção: composta pelas seguintes etapas: 1) planejamento e controle da produção (PCP); 2) corte (encai$\mathrm{xe}$, risco, enfesto e corte); 3) etapa costura; 4) beneficiamento e 5) acabamento.

A proposta da empresa AUDACES (2015) para o Ciclo Produtivo da Indústria do Vestuário (Figura 3) foi selecionada por abordar o ciclo de forma mais abrangente, visto que a empresa busca desenvolver tecnologias que possam 
fornecer apoio produtivo em todas as etapas. Quando a comunicação e a ligação entre as etapas do ciclo são realizadas de forma eficiente, é possível evitar desperdícios de tempo e de matéria prima e aumentar a produtividade.

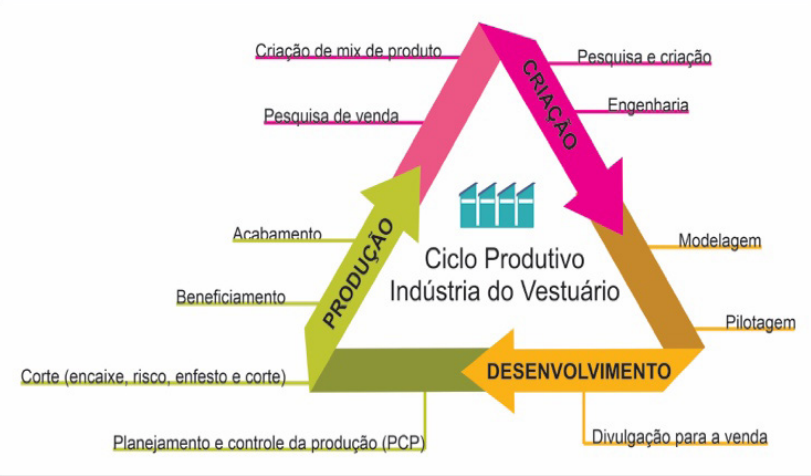

Figura 3. Ciclo produtivo da Indústria do Vestuário.

Fonte: Autores. Baseado na abordagem da AUDACES (2015).

\section{3. $O$ CASO DA EMPRESA $X$ MODA FESTA: DES- CRIÇÃO E ANÁLISE}

De acordo com o SINDIVESTU, o município de Uberlândia configura-se como grande polo das Indústrias do Vestuário no segmento Moda Festa (FIEMG/SINDIVESTU, 2019). Esse contexto, associado à atuação prévia no setor da moda e às preocupações com a sustentabilidade orientou a definição da pesquisa e a seleção do objeto de estudo aqui apresentado. Assim, após a revisão de literatura e as análises de dados do contexto local, a empresa foi selecionada por possuir as seguintes características:

- Estar localizada na cidade de Uberlândia;

- Pertencer ao segmento Moda Festa;

- Estar consolidada no mercado há 15 anos;

- Trabalhar com o sistema de pronta entrega, o que garante a produção de mais de uma peça por modelo;

Vale mencionar que, embora a empresa não tenha solicitado anonimato, optou-se por denominá-la X Moda Festa, a fim de resguardar sua privacidade.

Situada na cidade de Uberlândia/MG, a microempresa iniciou suas operações em agosto de 2005. De acordo com a terminologia adotada pela própria empresa, seu público-alvo é formado, principalmente, por jovens senhoras (40 anos a 50 anos) e senhoras (50 anos em diante) no segmento Plus Size, mas também destina parte de sua coleção ao público jovem (17 anos a 39 anos) e mais ousado. Trabalha com o sistema de pronta entrega, não atendendo ao público sob medida. A empresa atende muitas cidades da região como Uberaba, Patrocínio, Abadia dos Dourados, Monte Carmelo e Frutal, não possuindo clientes na cidade onde está situada. Além disso, não possui site próprio e opta por manter páginas em redes sociais para realizar suas divulgações.

Em termos de estrutura produtiva, a $X$ Moda Festa é de único proprietário e conta, atualmente, com dez funcionários trabalhando dentro da empresa e 28 terceirizados. Com produção média mensal de 170 peças, atende boutiques e lojas de aluguéis de todo o Brasil; entretanto a maior parte da sua produção está destinada às regiões Sul, Sudeste e Centro-Oeste. Com relação ao processo de produção e organização interna dos setores, a empresa desenvolve atividades de: Criação, Modelagem e Pilotagem, Corte, Tingimento, Costura, Bordado, Acabamento, bem como o Estoque peças prontas, descritas a seguir.

O estudo de caso foi realizado por meio de entrevistas com o proprietário da empresa juntamente a visitas técnicas realizadas nos dias 27 de fevereiro e 04 de março de 2020. O protocolo de entrevista foi elaborado seguindo as orientações propostas pela AUDACES (2015), Fletcher e Grose (2011) e Manzini e Vezzoli (2002), buscando compreender o ciclo de produção da confecção.

\subsection{Ciclo Produtivo da X Moda Festa}

Após a realização das visitas técnicas e da entrevista, as informações foram reunidas e analisadas, podendo nos orientar quando à forma produtiva da empresa, conforme descrita a seguir. Serão apresentadas duas etapas, sendo: 1) Etapas de Materiais e Processos; e 2) Etapas Subsequentes.

\subsubsection{Etapas de materiais e processos}

As etapas de Pesquisa de Venda, Criação de Mix de Produtos, Pesquisa e Criação, e Engenharia são realizadas simultaneamente, sendo o proprietário da empresa o responsável pelos resultados. Segundo informado na entrevista, existe uma abertura para sugestões de toda a equipe, principalmente da modelista e bordadeiras.

\section{- CRIAÇÃO}

As pesquisas realizadas são referentes às tendências mundiais de modelos, matéria prima e cores. Tendo como base a pesquisa de tendências, os modelos são criados (a empresa não realiza cópias) e os materiais (tecidos e aviamentos) que serão usados nas coleções são escolhidos, considerando-se a disponibilidade em estoque. Para completar os materiais faltantes (principalmente tecidos com cores que se igualam à cartela de cores definida), a empresa possui uma gama fornecedores (como importadores nacionais), mas ressalta que seria mais viável possuir apenas um para atender a toda sua demanda de cores. Os importadores estão localizados principalmente nos estados de São Paulo e Minas Gerais e os fabricantes dos tecidos e pedrarias são da China. 
Em geral, as coleções são compostas por 60 modelos, sendo divididos da seguinte forma: a) 10 modelos destinados ao público de jovens senhoras. b) 8 modelos ousados e elaborados, com alto custo de produção atendendo ao público de formandas e mães de noivos. c) média de 42 modelos para atender aos convidados de eventos tais como casamentos de fim de tarde, mais lisos e com pouco bordado.

Para a criação dos modelos, o proprietário apresenta suas ideias à modelista, que desenvolve os desenhos juntamente com ele. Na sequência, os desenhos são estilizados, mas possuem informações técnicas quanto ao tipo de tecido e quantidade usada, acabamentos e detalhes de modelagem, compondo assim a ficha-técnica da peça.

O proprietário também desenvolve os desenhos/riscos dos bordados em parceria com as bordadeiras pilotistas. Destaca-se aqui a criação de estampas exclusivas (serviço terceirizado): mesmo desenvolvendo poucas peças estampadas, a empresa busca o diferencial de oferecer estampas próprias. As fichas-técnicas são guardadas em um catálogo da coleção.

\section{- DESENVOLVIMENTO}

A profissional responsável pelos processos de Modelagem e Pilotagem é a modelista. Após a definição dos modelos, seguindo tabela de manequins com medidas padronizadas pela empresa, a profissional faz a interpretação em moldes de papel. De forma manual, utilizam-se as técnicas de modelagem plana e tridimensional (moulage/drapping) e durante o processo são realizados os testes para correções. Os moldes, depois de finalizados, contêm informações importantes que funcionam como orientações no processo de corte. A peça piloto é confeccionada juntamente com a modelagem, passando constantemente pela avaliação do proprietário da empresa e, ao final do processo, ambas estão aprovadas - modelagem base e peça piloto. Quando necessário, a peça piloto segue para a bordadeira pilotista realizar os bordados que também servirão como referência para as outras profissionais. A modelagem base e a peça piloto são feitas apenas em um tamanho, definido pelo proprietário de acordo com o modelo para posteriormente, ao final da coleção, também ser destinada para a venda. Durante a produção da peça piloto, o modelo também é precificado; assim, o proprietário consegue definir se os custos para a produção da peça são viáveis.

A equipe responsável pelo processo de Divulgação para as Vendas é composta pelo proprietário, pela gerente de produção e pelos representantes. Para a divulgação são utilizadas as peças pilotos e o portfólio, sendo o portfólio produzido após as peças piloto serem fotografas. A divulgação é realizada basicamente de duas formas: representantes e participação em feira de negócios. A empresa possui quatro representantes sendo que dois fazem a divulgação por meio dos mostruários e os outros dois fazem com os produtos de pronta entrega. Em média, eles dedicam uma semana para as divulgações na região próxima à Uberlândia e dois meses para a região Sul e para o estado de São Paulo.

A X Moda Festa já participou de outras feiras de negócios no Brasil, mas hoje participa apenas do Minas Trend (Feira de Moda Mineira que recebe expositores, compradores e formadores de opinião do todo o mundo), sendo a sua 14ª participação (desde o ano de 2013). Na feira, a empresa faz a captação de clientes das regiões Norte, Nordeste e Centro-Oeste.

\section{- PRODUÇÃO}

Nas etapas de Planejamento e Controle da Produção (PCP), Corte, Costura, Beneficiamento e Acabamento, o proprietário conta com o apoio da gerente de produção. A profissional, supervisionada pelo proprietário, cuida da organização e do planejamento das etapas sincronizando os fluxos da produção de acordo com as necessidades. As vendas realizadas pelos representantes são repassadas para a empresa diariamente; na sequência, a gerente de produção repassa os pedidos para a modelista e é nesse momento que se realiza a graduação dos moldes, de acordo com a grade vendida. Após a grade de moldes pronta, o pedido segue para o setor de corte, o qual conta com dois profissionais sendo a cortadeira e o seu auxiliar.

O processo de corte é realizado totalmente de forma manual. Primeiro o encaixe (posicionamento dos moldes sobre o tecido) é planejado, visando maior aproveitamento, e riscado. Posteriormente, os tecidos são enfestados (folhas de tecido sobrepostas) e cortados por máquinas operadas pela cortadora e por seu auxiliar. Após essa etapa, as peças cortadas são separadas e encaminhadas às costureiras. A gerente de produção também verifica o estoque de tecidos e pedrarias, avaliando se a empresa possui a quantidade para a fabricação dos pedidos feitos. Vale ressaltar que a verificação de estoque é realizada constantemente, antes da liberação dos pedidos, para evitar alguma dificuldade posterior na finalização do processo.

Atualmente, a X Moda Festa conta com três costureiras internas e outras três terceirizadas, que recebem as peças cortadas além da peça piloto para servirá de guia na produção. Após as peças prontas, elas são encaminhadas para o setor de bordado; no local é feita a separação da pedraria e, novamente, as peças são enviadas 
para as bordadeiras terceirizadas, sendo 25 profissionais. Finalizada a etapa de bordado, a peça retorna para a empresa e vai para o setor de acabamento. Duas profissionais são responsáveis por três procedimentos sendo: verificar se as costuras e o bordado das peças seguem as orientações da peça piloto; passar as peças e, por fim, etiquetar. Depois de finalizadas, as peças prontas seguem para o setor de estoque.

\subsubsection{Etapas Subsequentes}

\section{- DISTRIBUIÇÃO}

Depois de finalizadas as peças, a gerente de produção faz a separação de acordo com os pedidos, embala e encaminha para os clientes por meio de transportadoras, sendo o transporte custeado pela X Moda Festa.

\section{- CUIDADOS DO CONSUMIDOR E DESCARTE DE PEÇAS}

A empresa, em parceria com as boutiques, realiza os ajustes necessários no momento da venda, entretanto reparos no pós-venda não são realizados. A empresa também não possui um sistema de acompanhamento ou recolhimento das peças após o tempo de uso dos clientes.

\section{- CUIDADOS COM RESÍDUOS}

A XModa Festa não acompanha o quantitativo de retaIhos que são produzidos pela empresa. A separação dos retalhos é realizada de acordo com a classificação de tamanho e tipo de tecidos, da seguinte forma: os retalhos extremamente pequenos são descartados; as rendas são todas reaproveitadas na própria produção da empresa; os retalhos de malha são doados para uma artesã que produz tapetes para a venda (e oferece alguns para uso da empresa). No caso dos retalhos de tecido médios, estes são destinados a outra artesã que produz colchas de retalhos para uma instituição de caridade. Os retalhos grandes são reaproveitados pela própria empresa na produção de capas de almofadas para as funcionárias.

\subsection{Análise do Ciclo Produtivo da $X$ Moda Festa}

Partindo das orientações sobre o Ciclo de Vida dos Produtos sugerido por Manzini e Vezzoli (2002), sobre o Ciclo Produtivo na Indústria da Moda abordado por Fletcher e Grose (2011) e sobre o Ciclo Produtivo da Indústria do Vestuário abordado pela AUDACES (2015), foi realizada a análise do Ciclo Produtivo da empresa $X$ Moda Festa. A análise seguiu a mesma divisão de etapas e fases citadas pelos autores (Tabela 2).

\begin{tabular}{|l|l|l|}
\hline \multicolumn{2}{|l|}{ ANÁLISE - CICLO PRODUTIVO - $\boldsymbol{X}$ Moda Festa } \\
\hline Etapas & Fase & Subfases \\
\hline
\end{tabular}

\begin{tabular}{|l|l|l|}
\hline $\begin{array}{l}\text { Materiais e } \\
\text { Processos }\end{array}$ & Criação & $\begin{array}{l}\text {-Pesquisa de Venda; } \\
\text {-Criação de Mix de Produto; } \\
\text {-Pesquisa e Criação; } \\
\text {-Engenharia; }\end{array}$ \\
\cline { 2 - 3 } & Desenvolvimento & $\begin{array}{l}\text { - Modelagem; } \\
\text { - Pilotagem; } \\
\text { - Divulgação para venda; }\end{array}$ \\
\cline { 2 - 3 } & Produção & $\begin{array}{l}\text {-Planejamento e Controle } \\
\text { da Produção (PCP); } \\
\text {-Corte (encaixe, ris- } \\
\text { co, enfesto e corte); } \\
\text {-Costura, beneficiamen- } \\
\text { to e acabamento }\end{array}$ \\
\hline Distribuição & Sem divisão \\
\hline $\begin{array}{l}\text { Cuidados do } \\
\text { consumidor }\end{array}$ & Sem divisão \\
\hline Descarte & Sem divisão \\
\hline
\end{tabular}

Tabela 2 - Divisão de etapas referência para a análise do Ciclo Produtivo da empresa $X$ Moda Festa

Fonte: Autores

Além dos autores citados, utilizou-se ainda a referência de Sampaio et al. (2018) no trecho em que os autores destacam que a adoção das estratégias sustentáveis pelas organizações depende do seu estágio de maturidade quanto à sustentabilidade. Por esse motivo, a análise buscou compreender quais as ações sustentáveis que a empresa já possui e quais poderiam ser adotadas para ampliar o seu estágio de maturidade (Tabela 3).

\begin{tabular}{|l|}
\hline Níveis de Maturidade Sustentável de uma Empresa \\
\hline $1^{\circ}$ INATIVIDADE \\
\hline $2^{\circ}$ CONSCIÊNCIA \\
\hline $3^{\circ}$ EXPERIMENTAÇÃO REATIVA \\
\hline $4^{\circ}$ EXPERIMENTAÇÃO PROATIVA \\
\hline $5^{\circ}$ EXPANSÃO \\
\hline $6^{\circ}$ GESTÃO INTEGRADA \\
\hline $7^{\circ}$ ATUAÇÃO AMPLIADA \\
\hline
\end{tabular}

Tabela 3 - Níveis de maturidade Sustentável que as empresas podem apresentar (SAMPAI0 et al, 2018) Fonte: Autores.

A análise dessa perspectiva permitiu compreender que o proprietário da X Moda Festa, mesmo não possuindo formação em Design, possui valores pessoais que conduzem a empresa rumo à sustentabilidade direcionando adotando ações sustentáveis. Entretanto, conforme demonstram os autores Manzini e Vezzoli (2002), Fletcher e Grose (2011) e AUDACES (2015) percebe-se que é possível adotar mais ações com o intuito de ampliar o nível de maturidade sustentável da empresa. A Tabela 4 apresenta algumas possibilidades identificadas. 


\begin{tabular}{|c|c|}
\hline \multicolumn{2}{|c|}{ SÍNTESE DO ESTUDO DE CASO - AÇõES SUSTENTÁVEIS } \\
\hline \multicolumn{2}{|l|}{ Etapa: Materiais e Processos } \\
\hline \multicolumn{2}{|l|}{ FASE - CRIAÇÃO } \\
\hline $\begin{array}{l}\text { AÇÕES SUSTENTÁVEIS } \\
\text { ADOTADAS }\end{array}$ & AÇÕES SUSTENTÁVEIS POSSÍVEIS \\
\hline $\begin{array}{l}\text { - Constante avaliação do } \\
\text { estoque: verificação de tecidos, } \\
\text { pedrarias e retalhos de rendas } \\
\text { para utilização nas coleções; } \\
\text { - Tingimento de tecidos, pedra- } \\
\text { rias e rendas em estoque para } \\
\text { adequação de cartela de cores; }\end{array}$ & $\begin{array}{l}\text { - Escolha de fornecedores } \\
\text { comprometidos com a produção } \\
\text { de tecidos provenientes de } \\
\text { fibras de menor impacto; } \\
\text { - Atenção às condições de } \\
\text { trabalho dos funcionários; } \\
\text { - Escolha de fornece- } \\
\text { dores nacionais; }\end{array}$ \\
\hline \multicolumn{2}{|l|}{ FASE - DESENVOLVIMENTO } \\
\hline $\begin{array}{l}\text { AÇÕES SUSTENTÁVEIS } \\
\text { ADOTADAS }\end{array}$ & AÇÕES SUSTENTÁVEIS POSSÍVEIS \\
\hline $\begin{array}{l}\text { - Desenvolvimento de modela- } \\
\text { gem, peça piloto e ficha técnica, } \\
\text { ferramentas essenciais para } \\
\text { prever falhas, custos e direcio- } \\
\text { nar quanto aos acabamentos; } \\
\text { - Produção de peça piloto con- } \\
\text { forme perfil do cliente (medidas); } \\
\text { - Modelagem apenas na } \\
\text { grade vendida, sem desper- } \\
\text { dício de tempo e recursos; }\end{array}$ & \begin{tabular}{|l|} 
- Tingimento de tecidos e \\
aviamentos com tintas não \\
poluentes, contribuindo para \\
a não contaminação da água e \\
solo e do profissional no setor; \\
- Digitalização de moldes para \\
facilitar a realização da grade de \\
tamanhos e do plano de corte; \\
otimizar o tempo das tarefas \\
e armazenar digitalmente.
\end{tabular} \\
\hline \multicolumn{2}{|l|}{ FASE - PRODUÇÃO } \\
\hline $\begin{array}{l}\text { AÇÕES SUSTENTÁVEIS } \\
\text { ADOTADAS }\end{array}$ & AÇÕES SUSTENTÁVEIS POSSÍVEIS \\
\hline $\begin{array}{l}\text { - Estratégia do Planejamento } \\
\text { e Controle da Produção (PCP) } \\
\text { com fabricação guiada pelas } \\
\text { vendas, evitando desperdício } \\
\text { de insumos e tempo, minimi- } \\
\text { zando espaço para estocagem; } \\
\text { - Produção orientada por } \\
\text { ficha-técnica e peça piloto } \\
\text { garante qualidade e padrão dos } \\
\text { produtos, reduzindo erros e des- } \\
\text { perdícios de insumos e tempo; } \\
\text { - Separação de retalhos e } \\
\text { destinação a outras profis- } \\
\text { sionais que transformam } \\
\text { produzem novos produtos; } \\
\text { - Fornecimento de moldes } \\
\text { e fichas técnicas d coleções } \\
\text { passadas para pequenas } \\
\text { confecções, estimulando } \\
\text { os pequenos fabricantes; } \\
\text { - Redução da produção, garan- } \\
\text { tindo a qualidade dos produtos } \\
\text { e o bem-estar da equipe; }\end{array}$ & $\begin{array}{l}\text { - Automatização do processo } \\
\text { de mapeamento (encaixe) } \\
\text { dos moldes para o corte pode } \\
\text { reduzir a geração de retalhos. }\end{array}$ \\
\hline \multicolumn{2}{|l|}{ ETAPAS SUBSEQUENTES } \\
\hline \multicolumn{2}{|c|}{ Distribuição, Cuidados do Consumidor e Descarte } \\
\hline $\begin{array}{l}\text { AÇÕES SUSTENTÁVEIS } \\
\text { ADOTADAS }\end{array}$ & AÇÕES SUSTENTÁVEIS POSSÍVEIS \\
\hline $\begin{array}{l}\text { - Auxílio aos clientes no momen- } \\
\text { to da venda, quando há a neces- } \\
\text { sidade algum ajuste da peça. }\end{array}$ & $\begin{array}{l}\text { - Apoio aos usuários no } \\
\text { pós-venda, ofertando um } \\
\text { sistema de reparos, reformas e } \\
\text { até mesmo a coleta de peças } \\
\text { usadas, quando não forem } \\
\text { mais do interesse das clientes. }\end{array}$ \\
\hline
\end{tabular}

Tabela 4 - Síntese das ações sustentáveis já realizadas pela empresa e as ações sustentáveis possiveis Fonte: Autores.

\section{CONSIDERAÇÕES FINAIS}

Seguindo os princípios do Design sustentável e tendo como objeto de estudo uma microempresa do segmento moda festa na cidade de Uberlândia, a pesquisa teve como principal objetivo orientar as Indústrias do Vestuário quanto às ações sustentáveis possíveis de serem adotadas durante seu ciclo produtivo. Ressalta-se que, além dos critérios sustentáveis voltados ao meio ambiente, devido à grande importância para o setor de moda, o estudo não pode deixar de abranger questões voltadas ao âmbito social e econômico, entendendo que os três estão conectados.

Ao analisarmos as atitudes sustentáveis adotadas pela $X$ Moda Festa, mesmo de forma tácita, ou seja, sem a consciência da amplitude de suas práticas, percebemos que a empresa transita entre dois níveis de maturidade (SAMPAIO et al., 2018):

- o $2^{\circ}$ nível de maturidade - CONSCIÊNCIA - pois se preocupa com soluções para destinar de maneira adequada os retalhos produzidos, ampliando seu foco sobre as implicações ambientais geradas pelo negócio e buscando conhecimentos sobre o assunto e;

- $03^{\circ}$ nível de maturidade - EXPERIMENTAÇÃO REATIVA - pois busca práticas melhores, tanto ambientais quanto sociais; entretanto, a empresa ainda não reconhece a total importância das práticas.

Após todos os estudos realizados, entende-se que são possíveis adaptações graduais e transformações no atual modelo de produção das Indústrias do Vestuário no segmento Moda Festa, com características semelhantes às identificadas no estudo de caso realizado na cidade de Uberlândia. As adaptações poderão orientar as empresas em direção à sustentabilidade, transformando suas práticas cotidianas em ações mais sistematizadas e controladas, de forma a influenciar no seu nível de maturidade e ampliar sua consciência sustentável, especialmente dentro do segmento Moda Festa, mas não restrito a ele.

Observa-se que, atualmente, o maior conhecimento da sociedade sobre os impactos negativos causados pela produção industrial tem contribuído para que, cada vez mais, as empresas adotem princípios sustentáveis em suas práticas e estratégias de negócios (MANZINI e VEZZOLI, 2002; FLETCHER e GROSE 2011). Entretanto, é importante ressaltar que a transição rumo à sustentabilidade é um processo de longo prazo, mas que demanda ações imediatas, em diferentes escalas, e que possibilitem ampla colaboração e o acompanhamento permanente dos envolvidos, visto que envolvem recursos humanos e 
financeiros. Somente a partir de uma transformação coletiva das práticas cotidianas de produção e consumo será possível contribuir, efetivamente, para reduzir os impactos ambientais decorrentes do modelo produtivo vigente.

\section{REFERÊNCIAS}

AUDACES. O ciclo de desenvolvimento da peça de vestuário. Ano 2015. Disponível em < https://www. audaces.com/materiais-educativos/page/5/ >. Acesso em: 15/07/2018.

AVILA, Ana Paula S.; MACIEL, Dulce M. H.; SILVEIRA, Icléia; RECH, Sandra R. Os Resíduos Têxteis Sólidos no Contexto de Abordagens Sustentáveis: Ciclo de Vida, Economia Circular e Upcycling. MIX Sustentável, [S.I.], v. 4, n. 3, p.17- 24, out-mar. 2018. ISSN 24473073. Disponível em: <http://www.nexos.ufsc.br/index.php/ mixsustentavel>. Acesso em: 15/08/2019 https://doi. org/10.29183/2447-3073.MIX2018.v4.n3.15-22

BRAUNGART, M. MCDONOUGH, W. Cradle to cradle: criar e reciclar ilimitadamente. Tradução: Frederico Bonaldo. $1^{\circ}$ Ed. São Paulo: Editora G. Gili, 2013.

CESCHIN, F; GAZIULUSOY, İ. Design for Sustainability: A Multi-levelFrameworkfromProductstoSocio-technical Systems. 1. ed. Londres e Nova York: Routledge, 2020. 187 p. https://doi.org/10.4324/9780429456510-1

DMAE - Departamento Municipal de Água e Esgoto. Disponível em: < https://www.uberlandia.mg.gov.br/ prefeitura/orgaos-municipais/dmae/servicos-dmae/ coleta-de-residuos/ >. Acesso em: 29/06/2020.

FIEMG/SINDIVESTU. Federação das Indústrias do Estado de Minas Gerais / Sindicato das Indústrias do Vestuário de Uberlândia. Perfil Econômico do Setor. Disponível em: < http://www.fiemg.org.br/Default.aspx?tabid=8094 >. Acesso em: 15/08/2019.

FLETCHER, K.; GROSE, L. Moda \& Sustentabilidade: design para mudança. Tradução: Janaína Marcoantônio. São Paulo: Editora Senac, 2011, 192 p.

MANZINI, E.; VEZZOLI, C. O desenvolvimento de Produtos Sustentáveis. Os requisitos ambientais dos produtos industriais. São Paulo: EdUSP, 2002.

KAZAZIAN, Thierry. Haverá a idade das coisas leves. Tradução de Eric Roland René Heneault. São Paulo: Ed. Senac, 2005.

PAPANEK, V. Arquitectura e Design: Ecologia e Ética. Edições 70. Lisboa, Portugal, 1995

PIGOSSO, D .C. A., ROZENFELD, H., \& MCALOONE, T. C. Ecodesign maturity model: A management framework to support ecodesign implementation into manufacturing companies. Journal of Cleaner Production, n.59,
2013, p.160-173.

SAMPAIO, C. P. et al. Design para a sustentabilidade: dimensão ambiental. Curitiba, PR: Insight, 2018. 183 p; $15 \times 21 \mathrm{~cm}$.

STAHEL, W. The Product-Life Factor. In ORR, S. G (edited by). An Inquiry into the Nature of Sustainable Societies: The Role of the Private Sector. HARC Houston Area Research Center, 1982, 72-96p.

VEZZOLI, C. et al. Sistema produto + serviço sustentável: fundamentos / Carlo Vezzoli, Cindy Kohtala, Amrit Srinivasa; traduzido por Aguinaldo dos Santos. - Curitiba, PR : Insight, 2018. 178 p.; 15 × 21 cm 


\section{AUTORES}

ORCID:

ORCID:

\section{COMO CITAR ESTE ARTIGO}

BARROS, Stella Telles; NUNES, Viviane G. A. Sustentabilidade Na Indústria Do Vestuário: Estudo De Caso Em Uma Empresa Do Segmento Moda Festa. MIX Sustentável, [S.I.], v. 7, n. 2, p. 23-32, abr. 2021. ISSN 24473073. Disponível em:<http://www.nexos.ufsc. br/index.php/mixsustentavel>. Acesso em: dia mês. ano. doi:https://doi.org/10.29183/2447-3073.MIX2021. v7.n2.23-32.

DATA DE ENVIO: 30/07/2020

DATA DE ACEITE: 